\title{
Impact of Leadership Versus Organizational Effectiveness in the Secondary Banking Sector in Albania
}

\author{
Phd. Dritan Shoraj, \\ Lecturer, Faculty of Economy, \\ University of Tirana \\ Msc. Marionela Memetaj, \\ p-t assistent, Faculty of Economy, \\ University of Tirana
}

\begin{abstract}
Through an empirical and theoretical analysis, the study will demonstrate the relationship existing between the leadership style and organizational effectiveness, taking into account that the leadership model explored in this study will be the model provided by Bass and Avolio (1994), represented by the transactional, transformational and laissez-faire style. Impact and behavior of each style on the employees' motivation, increase of the business organization revenues and finally on the enhancement of organizational effectiveness. The research methodology selected for this study is the quantitative one, where a number of about 450 employees in the secondary banking system in Albania are planned to be interviewed. The measuring instrument will be divided in 4 sections and after data collection, the variable analysis will be realized via SPSS program, which enables the implementation of ANOVA test, Chi-square (X2), means, standard deviations, frequencies and correlations between the key variables to prove the study hypothesis. Finally, this scientific study will be closed with the relevant conclusions and recommendations.
\end{abstract}

Keywords: transactional leadership, transformational leadership, laissez faire leadership, organizational effectiveness, performance.

\section{Introduction}

Given that the Albanian society is still a society in transition, in terms of economic and socio-cultural aspects the Albanian business organizations can hardly identify with a particular model organizational success. The transition of the Albanian society from totalitarianism towards a market economy was obviously associated with their negative and positive effects. The impact of the regime strongly influenced the mentality of society or the organizational culture as a whole. Without underestimatingthe leadership behavior, which, as discussed below in the literature review, by supporting their work due to fear of punishment and reward, autocratic leaders were apt to imitate the followers according to their interests. Yet, can this kind of leadership style bring organizational effectiveness to the secondary banking system? Can that organizational culture of the totalitarian system function in a free market economy and competition between the banks of the second level in Albania? Or has the merger towards a market economy affected a change in leadership style, and this sector of the Albanian economy? These issues were the initial drive for launching this study, which is materialized below with specific steps to theoretical and empirical analysis.

Without doubt, all business organizations wish to be successful, but who makes them have a better performance and be more successful than competitors? According to many researchers, there are a number of variables that have an impact on the organizational effectiveness, but we can mention some of them, e.g. leadership style, organizational culture, organizational changes, organizational structure,strategy, technology etc. Organizational effectiveness, organizational performance, employees' satisfaction at work, as well as organizational changes are closely related to the style of 
leadership (Bass and Riggio, 2006; Drucker, 1974). As noted, the leadership style can motivate and stimulate employees to successfully overcome the difficulties faced by local and global competition (Luftman, 2004).

The paper aims to analyze and prove if the leadership has an impact on organizational effectiveness, and which of the leadership styles has a greater impact on the secondary banking system in Tirana. As a result, a research question of the paper is: What leadership model has the greatest impact on the organizational effectiveness and truly affects a leader in the organizational effectiveness of commercial banks in Tirana?

In order to support and respond to the research question, we have raised the null and alternative hypothesis $\left(\mathrm{H}_{1}\right.$ and $\left.\mathrm{H}_{0}\right), \mathrm{H} \rightarrow$ leadership style (transformational, transactional and laissez-faire) affects the organizational effectiveness of the secondary banking system in Tirana. The aim of this hypothesis is to analyze a more positive and comprehensive approach of what makes an effective leader (Holt etc., 2009) achieve organizational goals (Caldwell and Dixon, 2010).

Trends to encourage and motivate followers are useful to produce and develop self-esteem and confidence among the subordinates (Burns, 1978), in order to increase their involvement in the process and their responsibility. Bass and Avolio (1994) considered leadership as the verified influence of an individual's skill to change their behavior by changing their motivation. According to them, the leaders are divided into three types or categories: transformational, transactional and laissez-faire leaders.

\section{Literature Review}

The issue of the leader and his influence on business organizations for decades has become the subject of studies by many researchers, and moreover a more positive and complete perception of what makes a leader effective (Eagly, 2007; Holt etc., 2009; Jogulu, 2010). Notwithstanding that, the organizations of all sizes are engaged in organizations within a competitive environment and therefore they need effective leaders who understand the complexities of the always evolvingglobal environment; have intelligence, sensitivity and skill to motivate their followers in the effort towards excellence.

Accordingly, organizations need the right kind of leadership to survive the competition, because leadership is a key variable in the effective management of the business organization (Bell DeTienne, 2004).

Yet, this is clearly not an easy task. According to Cangemi (2011) etc., in a market that is shrinking and rapidly changing, the leader's vision or compliance plan and realization of organizational objectives may be based on already outdated assumptions (Fitzgerald, 2007), which can be put into challenging position the existence of the organization and part of its market. On the other hand, skills are required to transform them into advantages for decision making (Miller etc., 2008) and "wise choice" (Cangemi etc., 2008). Highly successful organizations focus on creating a comprehensive set of evaluation practices and leadership development in support of talents within the organization (Groves, 2007).

However, the leadership models have evolved and expanded beyond the influence and motivation they have offered to achieve organizational goals (Rosette and Tost, 2010; Caldwell and Dixon, 2010; Jogulu, 2010). It is clear that the trends to encourage and motivate followers are useful to produce and develop self-esteem and confidence among subordinates (Burns, 1978; Jogulu, 2010), in order to increase their involvement in the process and their responsibility.

Bass and Avolio (1994), considered leadership as the verified influence an individual's skill to change their behavior by changing their motivations. According to them, the leaders are divided into three types or categories: transactional- type of leader that uses the mechanism of control and rewards to motivate the external level; transformational - the kind of leader that uses bonuses to increase the commitment and motivation at domestic level; and or laissez-faire (nonintrusive) - leaders that offer no response or support to their followers.

Bass and Avolio (1994) considered styles of transactional and transformational leadership as distinct, but not mutually exclusive. They accepted that the same leader can use both types of styles of leadership at different times and situations, e.g. the unexpected reward is an effective leadership style, but is not as effective when used with transformational factors (Roper, 2009). According to the behavior of transactional and transformational leadership, (Bass, 1985), the effect and inspirational leadership appear when the leaders predicts the desirable future and clearly demonstrates how to achieve this, establishing high performance standards and determination to fulfill the goal. Further, the followers wish to identify themselves with the type of leadership, the leader in turn helps followers become more innovative and creative through the intellectual or material stimulation, in the leadership focus (Erkutlu, 2008). 


\section{Transactional leadership}

Bass and his colleagues, based on the early work of Burns, concluded that a transactional leadership model was the one who exploited a transaction between leaders and followers, who were then rewarded or disciplined based on work results (Bass and Avolio, 1994; Bass, etc, 1996; Jogulu, 2010). They drew the conclusion that transactional leaders must be excellent communicators, in order to clearly define the objectives for employees. They apply rewards to encourage achieving or exceeding the objectives and penalties for non-compliance.

While identifying individual strengths of the subordinates, they draw up agreements with subordinates based on rewards and incentives in relation to the results to be achieved (Bass and Avolio, 2000).According to Bass and Avolio (1994), transactional leadership is the typical focus of the basic management, using bonuses as a control mechanism to motivate followers at external level, or the exchange relationship between leader and followers to fulfill their personal interests. According to many researchers (Burns, 1978; Bass, 1998; Bass and Avolio, 1994; Gibson, etc., 1997; Northouse, 2001), transactional leadership may appear in two forms of management: active leadership, by exception: the leader monitors the performance of followers and undertakes corrective measures if the follower does not meet standards; or the form of passive leadership, leader practicing passive management by exception, waiting to show problems before taking corrective measures or performs a delegating role and avoids any measures. Therefore, as we see from the above literature, the focus of transactional leader to enhance the follower's motivation and fulfillment of organizational objectives is through punishment-reward model to achieve performance.

\section{Transformational leadership}

The concept of transformational model was first highlighted by Burns (1978) in a context of political science and was later formulated in the theory of organizational leadership by Bass (1985). According to Burns approach, transformational leaders motivate their followers to perform beyond expectations, using bonuses to increase the followers' commitment and their internal motivation (Bass and Avolio, 1994).

The increase of followers' trust is also associated with the motivation to overcome their personal interests to the benefit of the group, or organization (Northouse 2001, Bass and Avolio, 1994), and consequently a higher support for increased organizational effectiveness. By further deepening the approach of Burns and his colleagues (Bass, 1985; Bass and Avolio, 1994, 1995) identified the components of Transformational Leadership behavior as idealized features; idealized influence; inspirational motivation; intellectual stimulation and individualized analysis (Bass and Avolio, 2004).

Hence, these are the distinguishing features of the other leaders, but also make them more susceptible to the result (Crawford, 2005), and better able to handle the technical aspects from the workplace rather than transactional or delegating leaders (Crawford, 2005), transformational leadership is supposed to foster creativity (Kahai etc., 2003; Shin and Zhou, 2003), to stimulate followers to see problems in new ways; contribute to develop their full potential, which can result in more positive creativity of the followers ( Jong and Hart, 2007) and growingly effective leadership (Mandell and Pherwani, 2003; Jogulu, 2010) because it is essential for the development of subordinates and creating environments that promote continuous learning. Yet, not everyone thinks so. An experiment conducted by Jaussi and Dionne (2003), discovered low impact of transformational leadership on creativity. However, it is worth to mention that there are many researchers who have the same access to Jaussi and Dionne (Jong and Hartog, 2007).

In conclusion, according to some researchers (Bass and Avolio, 1990; Northouse, 2001), the transformational leadership brings greater effects than transactional leadership because transactional leadership leads to the expected results, while transformational leadership leads to performance that exceeds expectations of outcomes (Lowe, etc., 1996; Erkutlu, 2008).

\section{Liberal Lleadership (laissez-faire)}

Liberal style (laissez faire) is based on a very limited use of power, leaving subordinates a greater degree of freedom in their activities. Leaders define some very broad limits and letsubordinates define the objectives by themselves and the 
manner of their implementation, thus playing a role rather of a supporter than of a superior. Accordingly, this type of leader provides subordinates the right information serving as a link with the external environment.

According to Bass and Riggio (2006), liberal leadership is the kind of leader that in itself is oriented towards avoidance or lack of leadership. Liberal leaders do not make decisions, delay actions, ignore responsibilities, do not use any kind of power and avoidthemselvesby not getting involved.

According to Bass and Riggio (2006), laissez - faire is inactive and ineffectiveleadership. Contrary to the transactional and transformational leadership, the liberal leadership has proven to be a completely unproductive management approach. Corrigan, etc. (2000) write: "The laissez - faire leader is restrained, uninvolved and disinterested in the daily activities of the treatment team". According to them, the laissez - faire leadership had a negative impact, but consumers had a lower level of satisfaction and poorer life quality. Corrigan et al (2000) concluded that there was an inverse correlation between style and customer satisfaction that leadership and laissez - faire leadership, and a positive relationship between both transactional and transformational leadership.

\section{Research Methodology}

This paper is based upon positivist approach to ontological objectiveposition, where social reality is existent and can be studied as independent by us as researchers (Bob Matthews and Liz Ross, 26).Knowledge of the phenomenon of leadership style in organizational effectiveness through employee performance growth is based on what we as researchers can observe and record from the reality, being objective in relation to it, with no impact on data and surveyed subjects. The study hypotheses derived from existing reality, and contain casual links between two study variables as leadership style andorganizational performance.

Factual data of easily observable values obtained from the survey with 433 employees or around $11 \%$ of the employees in the secondary bank system in Tirana city, are used to prove the hypotheses. The data will be encrypted and then will be analyzed through the statistical program SPSS (Statistical Package for Social Sciences, version 20). Average, standard deviation, frequency and other statistical data will describe the characteristics of sample population. Testing of hypotheses will be performed through Chi-square test $(x 2)$ where proper statistical level is acceptable at the quota of $p$ $<.05$.

Of these 301 women and 13 men were interviewed. We contacted all the human resources departments of all banks, where it transpires that the total number of employees of the second level banks in Albania is around 6700 , and the total number of employees in the secondary banking system in Tirana is 4280 , specifically it is about $64 \%$ of the total. Random sampling is done by calculating the number of subsidiaries with the number of employees and the number of interviews for each bank.

The first section of the questionnaire was demographic one, whereby further demographic characteristics of the sample population were analyzed, where according to the analysis the sample is dominated by $22-30$ year old persons, thus representing $60.3 \%$ and $31-40$ years old constitute $27,2 \%$ of the respondents. As mentioned above, the number of participating women employed at second level banks in Tirana is 301 or $69.5 \%$ of the sample population, while men employed in this sector are 132 or $30.5 \%$ of the sample population.

According to data obtained from the quantitative analysis of the frequency, it results that 57 employees are Bachelor graduates or $21.2 \%$ of respondents, 232 or $53.6 \%$ of the sample hold a Master of Science degree and only 2 employees or 0.4 of the sample population hold a Doctorate degree, the latter being senior managers at the bank where they practice their profession.

\section{Data Analysis}

Based on the econometric model, we already check if there is an express link in the hypothesis of this paper. The hypothesis $\mathrm{H}_{0} \rightarrow$ leadership style (transformational, transactional and liberal (laissez-faire)) affects the organizational effectiveness. Accordingly, the independent variables are transformational, transactional and laizer-faire (let us refer them as L1, L2 and L3 in software), while the dependent variable is organizational effectiveness. Results are as follows:

$\operatorname{lm}($ formula $=$ effect $\sim \mathrm{L} 1+\mathrm{L} 2+\mathrm{L} 3$, data $=\mathrm{y}$ ) 
Residuals:

Min Median $1 Q \quad 3 Q \quad$ Max

$-1.58824-0.22599-0.006840 .230780 .86624$

Coefficients:

Estimate Std. Error $t$ value $\operatorname{Pr}(>|t|)$

(Interc) $3.844590 .08790 \quad 43.737 \quad 0^{* * *}$

Coefficients alpha reliability P-value less than $5 \%$

$\begin{array}{llllr}\text { L3 } & 0.02847 & 0.002454 & 11.460 & 0 \text { *** } \\ \text { L2 } & 0.06001 & 0.02306 & 2.602 & 0.00959 \text { ** } \\ \text { L1 } & 0.07215 & 0.01974 & 3.654 & 0.00029 \text { *** }\end{array}$

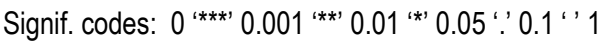

Residual standard error: 0.3527 on 433 degreesoffreedom

Multiple R-squared: 0.1032, Adjusted R-squared: 0.09691

F-statistic: 16.49 on 3 and 433 DF, p-value: $3.692 e-10$

As noted above, all variables, without exception remain in the equation. We graphically present these results as below. Hence, weconfirmed that there is a clear impact of leadership (transformational, transactional, laissez faire)

in the organizational effectiveness. It is noted that the greatest influence belongs to the variable of 'transformational leadership'. The signs are all positive, so we have a fair/proportionalrelation, the growth of each of the independent variables is associated with the increase of the dependent variable (organizational effectiveness). A more complete picture is presented in the chart no 1.

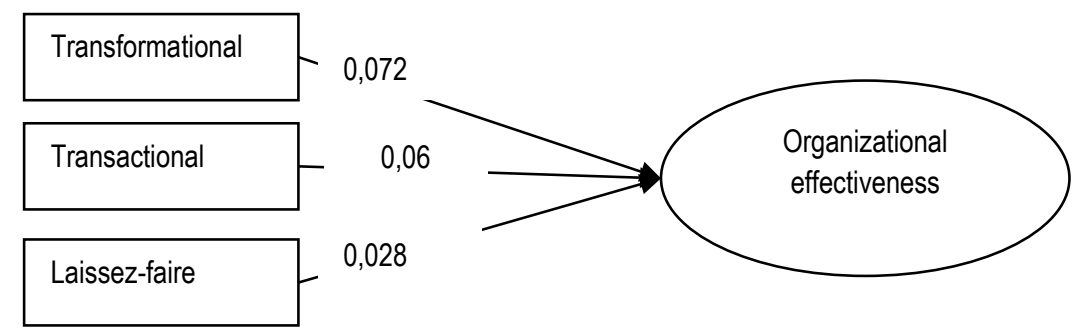

As it can be seen from the figure, each increase unit in transformational style is affected by an increase of $7,2 \%$ in organizational effectiveness. Further, as for each increase unit in transactional leadership style, there is a growth impact by $6 \%$ in organizational effectiveness. Finally, any increase unit in laisser-faire style of leadership corresponds to an increase in organizational effectiveness by $2.8 \%$. In conclusion, the study hypothesis: $\mathrm{H}_{0} \rightarrow$ leadership style (transformational, transactional and laissez-faire) affects the organizational effectiveness, is proven.

By interpreting data obtained from the software analysis, the results graphically presented below, making the relevant interpretation as below, on a case by case basis, for each variable. Based on the above data, as for the coefficient of the gender variable, it means that in our case males increase (on average) the organizational effectiveness by $8 \%$, compared to women. Apparently, $3 \times 1$ ratio of men to women reduces productivity. 
Finally, the coefficient of education variable means that with the increasing level of education of workers with a higher degree (eg, from Bachelor to Master), the organizational effectiveness is increased by $6 \%$. Hence, there is a positive relationship in the ratio of $1: 6 \%$ between these two variables.

\section{Conclusions}

Thus, according to analyzes, three main styles were elaborated, such as the transformational, transactional, and liberal ones. All these study variables were correlated to test their impact on organizational effectiveness and analysis of the study data showed that all the hypotheses set out at the beginning of the paper demonstrate statistical significance mainly at $5 \%$ and stability, thus asserting that study hypotheses are proven. Specifically, regarding the hypothesis of this study, stating that the style of leadership (transactional, transformational, liberal) affects the organizational effectiveness, shows that all independent variables such as transactional, transformational and liberal leadership show a positive statistical stable relationship with the organizational effectiveness as a dependent variable. The highest values are introduced for the transformational leadership, which implies that this leadership style has a greater impact than others in the organizational effectiveness of commercial banks.

In analyzing the demographic section of the measuring instrument, the results demonstrated that gender, education have a direct impact on the organizational effectiveness. Specifically, the coefficient of the gender variable sex demonstrated that men increase, on average, $8 \%$ of the organizational effectiveness compared to women in the sector. Apparently,the high ratio of women in this system may be one of the latent variables having an adverse impact on the organizational effectiveness. Accordingly, the effectiveness is increased by $8 \%$ for each unit (1/3) of the increase of ratio between women/men. One cannotforesee how many similar units could be affected enhance organizational effectiveness after this element has not been a focus of study, but these are secondary data that have emerged during this study.

Finally, another key variable that has an impact on the organizational effectiveness is education of employees. A data analyses showed an increase of $6 \%$ of the organizational effectiveness with the upgrading of education to a higher level, namely, the transition from the first cycle of graduate (Bachelor) studies to Professional Master or from the latter to Master of Science, the organizational effectiveness is increased by $6 \%$.

Even in this case, one cannot foresee the number of the increase units of the educational level to which the growing impact on the organizational effectiveness will be applied. All these variables clearly show that gender, age and education have a direct impact on the organizational effectiveness of second level banks in Tirana. These may be matters of interest to be explored in the future.

\section{References}

[1] Bass, B. (1985), "Leadership and performance beyond expectations", New York: Free Press.

[2] Bass, B., Avolio, B. and Atwater, L. (1996), "The transformational and transactional leadership of men and women", Applied Psychology: An International Review, Vol. 45, pp. 5-34.

[3] Bass, B.M. (1998), Transformational Leadership: Industrial, Military and Educational Impact, Lawrence Erlbaum, Mahwah, NJ.

[4] Bass, B.M. and Avolio, B.J. (2000), Effects on Platoon Readiness of Transformational/Transactional Platoon Leadership, US Army Research Institute for the Behavioral and Social Sciences, Orlando, FL.

[5] Bass, B.M. and Avolio, B.J. 1994. Improving organizational effectiveness through transformational leadership. Thousand Oaks, CA: Sage Publications.

[6] Bass, B.M. and Riggio, R.E. (2006), Transformational Leadership, Erlbaum, Mahwah, NJ.

[7] Bell De Tienne, K., Dyer, G., Hoopes, C. and Harris, S. (2004), "Toward a model of effective knowledge management and directions for future research: culture, leadership, and CKOs", Journal of Leadership and Organizational Studies, Vol. 10 No. 4, pp. 26-43.

[8] Burns, J.M. (1978), Leadership, Harper Torchbooks, New York, NY.

[9] Burns, J.M. (1978), Leadership, Harper Torchbooks, New York, NY.

[10] Caldwell, C. and Dixon, R. (2010), "Love, forgiveness and trust: critical values of the modern leader", Journal of Business Ethics, Vol. 93, pp. 91-101.

[11] Caldwell, C. and Dixon, R. (2010), "Love, forgiveness and trust: critical values of the modern leader", Journal of Business Ethics, Vol. 93, pp. 91-101. 
[12] Cangemi, J. et. al (2011), "Successful leadership practices during turbulent times "Journal of Management Development, Vol. 30 No. 1, pp. 30-43

[13] Cangemi, J., Burga, W., Lazarus, H., Miller, R. and Fitzgerald, J. (2008), "The real work of the leader: a focus on the human side of the equation", Journal of Management Development, Vol. 27 No. 10, pp. 1026-36.

[14] Drucker, P.F. 1974. Management: Tasks, responsibilities, practices. NY: Harper and Row.

[15] Eagly, A.H. (2007), "Female leadership advantage and disadvantage: resolving the contradictions", Psychology of Women Quarterly, Vol. 31, pp. 1-12.

[16] Erkutlu, H. (2008), "The impact of transformational leadership on organizational and leadership effectiveness", Journal of Management Development, Vol. 27 No. 7, pp. 708-726.

[17] Fitzgerald, J. (2007), From Data to Dollars: Better Decisions through Analytics, Fitzgerald Analytics, New York, NY.

[18] Gibson, J.L., Ivancevich, J.M. and Donnelly, J.H. (1997), Organizations: Behavior, Structure, Process, Rob Zwettler, New York, NY.

[19] Groves, K. (2007), "Integrating leadership development and succession planning best practices", Journal of Management Psychology, Vol. 26 No. 3, pp. 239-60.

[20] Holt, S., Bjorklund, R. and Green, V. (2009), "Leadership and culture: examining the relationship between cultural background and leadership perceptions", Journal of Global Business Issues, Vol. 3, pp. 149-64.

[21] Jaussi, K.S. and Dionne, S.D. (2003), "Leading for creativity: the role of unconventional leader behavior", Leadership Quarterly, Vol. 14 Nos 4/5, pp. 475-98.

[22] Jogulu, U. (2010), "Culturally-linked leadership Styles", Leadership \& Organization Development Journal Vol. 31 No. 8, pp. 705-719.

[23] Jong, J and Hartog, D. (2007), "How leaders influence employees' innovative behavior", European Journal of Innovation Management, Vol. 10 No. 1, pp. 41-64.

[24] Kahai, S.S., Sosik, J.J. and Avolio, B.J. (2003), "Effects of leadership style, anonymity, and rewards

[25] Lowe, K.B., Kroeck, K. and Sivasubramaniam, N. (1996), "Effectiveness correlates of transformational and transactional leadership: a meta-analytic review of the MLQ literature", Leadership Quarterly, Vol. 7 No. 3, pp. 385-426.

[26] Mandell, B. and Pherwani, S. (2003), "Relationship between emotional intelligence and transformational leadership styles: a gender comparison", Journal of Business and Psychology, Vol. 17, pp. 387-404.

[27] Miller, R., McVeigh, B., Mamaril, D. and Cangemi, J. (2008), "Best practices of credit union leaders: a four country study", paper presented at the World Council of Credit Unions Annual Conference, Hong Kong, 12-17 July.

[28] Northouse, P.G. (2001), Leadership Theory and Practice, 2nd ed., Sage Publications, Thousand Oaks, CA.

[29] Roper, E. (2009), "the relationship between organizational culture, Management leadership style and organizational Commitment and their impact on organizational Outcomes in a high-technology organization", Huntsville, Alabama.

[30] Rosette, A. and Tost, L. (2010), "Agentic women and communal leadership: how role prescriptions confer advantage to top women leaders", Journal of Applied Psychology, Vol. 95, pp. 221-35.

[31] Shin, S.J. and Zhou, J. (2003), "Transformational leadership, conservation, and creativity: evidence from Korea", Academy of Management Journal, Vol. 46 No. 6, pp. 703-14. 